\title{
A Brief Analysis of Application of Case Method of Instruction in Automobile Design Course Teaching
}

\author{
Liang Jiao \\ Baoji Vocational Technology College, Baoji Shaanxi, 721001, China
}

Key words: Automobile design course, Case-based Teaching, Application.

\begin{abstract}
As one of the required courses for automobile majors, automobile design course has an extensive application value in some specialized courses, such as automobile structure, auto mechanical design, engineering mechanics, electronic instrument, etc. It is an important technical service in these courses, and also a specialized course that vocational education students must be proficient in for getting engaged in automobile design in future. Automobile design course is one of the specialized courses in the automobile engineering field, covering automobile mechanics, electronic technology, and engineering mechanics. By taking this course, students can learn to make comprehensive assessment on automobile structure and performance, and scientifically select a structure design scheme and related parameters. Automobile design course actually is a course requiring students to have strong operating ability, and the knowledge should be applied widely and put into practice. Hence, we should focus on how to effectively link the knowledge points in teaching process. The case method of instruction can largely facilitate automobile design course. In this paper, the application of the case method of instruction in automobile design course teaching is analyzed based on the actual situation, with a hope to help the peers.
\end{abstract}

\section{Introduction}

Automobile design course plays an important role in China's automobile specialty development and the automobile making field, and is an important elective course for vocational education students. It is a subject based on automobile structure design, automobile theory, mechanical structure design, and auto electrical technology. In automobile engineering and automobile making teaching, guiding students to have an in-depth study of related courses of automobile design is helpful for students to develop a systematic knowledge of the system structure, and know better about automobile performance, to lay a solid technological base for getting engaged in automobile design in future. But we also should clearly recognize that there are many problems in the teaching process of automobile design course. Fortunately, the case method of instruction can effectively solve various problems in teaching process, to improve teaching quality and efficiency.

\section{Characteristic Analysis of Application of Case Method of Instruction in Automobile Design Course}

\section{Characteristic Analysis of Automobile Design Course}

The main characteristic of automobile design course is that it is about automobile structure, and covers basic theoretical knowledge of entire automobile design and entire chassis design, mainly including automobile overall design, automobile clutch selection, transmission determination, transmission shaft, drive equipment, suspension, steering system and braking system. In concrete learning process, students are required to be able to put what they have learned into practice. In the teaching process of automobile design course, if the "Duck-stuffing" type of teaching is followed, 
and students' experience and feelings are ignored, students' learning initiative will be largely impaired. Furthermore, this dull teaching mode will isolate teacher from teachers, so that they have little communication, interaction and exchange. Finally, only barely satisfactory teaching effect will be achieved. If the case method of instruction is introduced into automobile design course teaching, effective bilateral interaction between teacher and students can be realized. In the learning process, it should not be that a teacher uniaxially imparts knowledge to students. In stead, teacher and students should actively interact with each other to finally construct a structure of knowledge. In any teaching activities, teacher should let students play the dominant role and actively construct their own structure of knowledge rather than uniaxially impart knowledge to students. Before taking the automobile design course, students have had a base of related specialized knowledge, and they have their own viewpoints and opinions on this course. Hence, it is unnecessary to repeat what the book says in the teaching process. In stead, teacher should train students to develop the ability of problem solving, which can be realized with the case method of instruction.

\section{Characteristic Analysis of Application of Case Method of Instruction in Automobile Design Course}

Case method of instruction refers to put teaching cases in classroom teaching to realize certain teaching objectives, of which the steps include case show, case analysis, case summarization and practice. Case method of instruction is a new teaching system. The application of case method of instruction in automobile design course have many characteristics, among which the prominent one is to explain unique features in combination with case features, so as to figure out the general features. The specific application process is started with practical case, then specific questions will be raised, teacher and students will discuss about and analyze a certain question together, and finally obtain a solution. This kind of teaching mode is useful for both teacher and students to interact with each other, in which teacher can help students to solve problem, make discussions and analysis of questions, expand the ability of thinking, and draw inferences about other cases from one instance. It is thus clear that the case method of instruction is that teacher guides students into a specific teaching environment in a scientific case situation specially created for students, so as to fully reflect the prepared case situation, guarantee full participation of students, and improve students' ability of problem solving.

\section{Analysis of Problems in Automobile Design Course Teaching}

\section{Students don't fully understand the importance of automobile design course.}

Under the influence of traditional teaching philosophy, most teachers of automobile design course follow the traditional teaching mode. In this mode, teachers are dominant and authoritative in classroom, and students can do nothing but passively accept knowledge. Thus, students cannot acquire enough knowledge of automobile design course, and lack their own understanding on related knowledge systems in the course. Many students just take automobile design course as an elective course, have no idea about the importance of the course, and fail to concentrate on in classroom or do homework carefully. Thus, their cannot lay a solid foundation of theoretical knowledge or develop a strong operating ability either. Such students can hardly be competent for their job (such as making comprehensive analysis of various data) and meet the requirements for high-quality automobile design talents in modern society. In the traditional teaching mode, students' can hardly play the dominant role in classroom, have a weak consciousness of active learning, and cannot have their professional abilities largely improved.

\section{There is no high-quality curriculum design.}

The automobile design course covers knowledge and contents of several fields and subjects, and contains complicated and tiny knowledge points. And students are required to grasp a large amount of knowledge points and contents. In the teaching process, not only the parts and elements of automobile 
transmission system and the calculation methods should be imparted, but also students should be supposed to learn to draw automobile driving axle. Besides, students also should be trained to fulfill certain design tasks with quality guaranteed. But in real teaching process, many students are incapable of fulfilling the assigned design tasks as required. This is because they haven't grasped the theoretic knowledge, and not developed a strong operating ability either. Most students perform unsatisfactorily in actual tasks, such as design, compilation of specification, and so on. Even some students produce a designing scheme in which the design instruction doesn't conform to the real content, which will greatly influence the quality of design.

\section{Students don't have a solid knowledge foundation.}

Automobile design course is a subject that requires students to have a solid foundation of theoretic knowledge. Any student who intends to take this course must have had a solid foundation of theoretic knowledge. To this end, he must learn the required courses well. Only he has a solid foundation of theoretic knowledge, he can learn the automobile design course with facility. But the fact is that many students haven't had a solid foundation of theoretic knowledge, such as mechanical drawing, tolerance fitting, measuring technique, and engineering mechanics, and developed a strong operating ability either, especially of making and drawing, which is adverse to students' subsequent learning of automobile design course. That students are weak in basic knowledge is mainly reflected in the following aspects. Firstly, they cannot accurately determine the surveying, mapping and view locations in surveying, mapping and drawing design, which results in that many parts and components cannot be connected well if the assembly drawing is followed, and it is difficult to dismantle and assemble the parts and components. Secondly, they design the standard size of some parts and components at random, can not clearly compile the center line of section of parts and components and the title block in detailed according to the standard and technical requirements.

\section{Analysis of Application of Case Method of Instruction in Automobile Design Course Collect information for scheme making}

Professional teachers of automobile design course should have approximately understood the development situation and trend of local and state automobile industry before determine a proper scheme, so as to ensure that they have adopted the latest materials and cases that can fully reflect the latest trend of the automobile industry. Meanwhile, they also must proper process and sort the collected case data and resources in combination with the characteristics of the specialty first, and then compile teaching materials suitable for the students on this basis. In the process of teaching material compilation, the focus should be always on the general structure and inside and outside layouts of automobile, the automobile assembly should be always taken as a branch of case teaching, typical and representative vehicles should be taken as the main carrier of case teaching to provide a rational technical parameter range to students, and students' problems should be promptly analyzed, explained, resolved and calculated. The aim of case teaching is to enable students to participate in classroom teaching, to develop the operating ability, learn to analyze and summarize results, discuss with other classmates and the teacher on design procedures and design philosophy, promote work in all areas by drawing upon the experience gained on key points, and finally grasp the basic contents and knowledge of automobile design course. Thus, after fulfilling the assigned analysis tasks, students can tackle the tasks of calculation and analysis according to the kinetic parameters of automobile, present their scheme design drawing based on the calculations and a proper design scheme, and check the calculations finally. With the case method of instruction, teacher can put cases into automobile design course teaching, so that students can learn the ability of problem solving via practice with the specialized theoretic knowledge they learned before. Comparing with the traditional "Duck-stuffing" type of teaching, the case method of instruction is more vivid and visual. 


\section{Create good learning situation for students based on cases.}

In the process of applying case method of instruction in automobile design course teaching, teachers also should give proper guidance to students, create a good learning situation for students, and enlighten and guide students to participate in classroom teaching. Specifically, teachers should create a positive, harmonious and relaxing learning situation. Thus, students can apply what they have learned to solve problems presented in the cases well, learn to independently think about problems, and communicate and interact with teachers. Besides, an active atmosphere can be created, and students can learn to have reflective learning. A good learning atmosphere can stimulate students' learning ability, and largely improve students' learning effect.

\section{Attach importance to evaluation of case method of instruction.}

In addition to collection, sorting, compilation and application of materials, the last key link is to comprehensively analyze and evaluate the application effect of cases, and present the final calculations and analysis results in writing form. For novel and innovative contents, teachers should not be grudging of giving encouragement; for problems, corrective measures should be taken timely, so as to develop a hierarchical and advanced design method.

\section{Matters requiring attention in application of case method of instruction.}

As to automobile design course teaching process, the case method of instruction has many advantages, and there are many related achievements. Since the case method of instruction is just one method of classroom teaching in which students can improve their operating ability, however, its effect is much inferior to that of practical teaching, because students have few chances of practice in classroom teaching. In view of this, the case method of instruction is not omnipotent in automobile design course teaching process, and it also has disadvantages. For teachers, the case method of instruction is actually an overall structure of teaching activities, and whether the teacher holds an advanced teaching thought will have a profound influence on the teaching effect. For students, the case method of instruction is a learning platform and carrier that is good for increasing students' participation in classroom teaching. For case selection, it is better to select the latest cases, continuously enrich and improve case contents in combination with the development of times, timely remove the obsolete case contents, and constantly add new contents. It is unadvisable to indiscriminately copy the previous teaching materials. In the process of applying real cases, various teaching means should be combined together to facilitate interactions between teacher and students, so as to truly put case teaching into full play.

\section{References}

[1] Our School Won the Second Prize in 2012 China Automobile Design Competition Judging Panel Special Award Points with Nissan Defflo Concept Vehicle, Journal of Wuyi University (Natural Science Edition), 2012(02).

[2] Zhang Guowang. Innovative Practice of Case Method of Instruction-On the Innovative Research and Application of Case Method of Instruction Compiled by Zhang Yinghua et al, Modern Finance and Economics- Journal of Tianjin University of Finance and Economics, 2008(07).

[3] Ren Guoqiang, Luo Xiaofeng. Application of Case Method of Instruction in Teaching of Basis of Mechanical Designing, Journal of Sichuan Vocational and Technical College, 2011(01).

[4] Zhang Baojian, Jiang Haibing. Observation of Teaching Effect of Clinical Case Teaching Method in Intensive Care Unit of the Department of Cardiology, Chinese and Foreign Medical Research, 2016(19). 
[5] Bao Siqin. Analysis of Application of Case Method of Instruction in Constitution Teaching, Journal of Inner Mongolia Normal University (Educational Science Edition), 2016(06).

[6] He Xuxi. Humble Opinions on Application of Case Method of Instruction in Contract Law Course Teaching, Legality Vision, 2016(23).

[7] Zhang Lijun. Discussions on Application of Case Method of Instruction in VisualFoxPro Course Teaching, China Management Informatization, 2016(15).

[8] Feng Juan, Yang Tianshu, Zheng Yuanzhi, Ren Quanbo, Li Xiaopeng, Zhao Yue. Practice and Exploration of Carrying out “Nonlinear Circuit Chaos Effect” Experiment, China Electric Power Education, 2014(02). 